\title{
Postergación de la maternidad en Chile: Una realidad oculta
}

\author{
ARIEL FUENTES ${ }^{1}$, CRISTIAN JESAM ${ }^{1}$, LUIGI DEVOTO ${ }^{1}$, \\ BLANCA ANGARITA ${ }^{1}$, ANDREA GALLEGUILLOS ${ }^{1}$, \\ ANDREA TORRES ${ }^{1}$, ANTONIO MACKENNA ${ }^{2}$
}

${ }^{1}$ Instituto de Investigaciones Materno Infantil (IDIMI) Facultad de Medicina, Universidad de Chile. Hospital Clínico San Borja Arriarán 2 Unidad de Medicina Reproductiva, Clinica Las Condes.

Trabajo parcialmente financiado por FONDAP

Grant 15010006-8

Recibido el 11 de marzo de 2010, aceptado el 27 de septiembre de 2010 .

Correspondencia a: Dr. Ariel Fuentes Hospital Clínico San Borja Arriarán: Santa Rosa 1234 $2^{\circ}$ piso (IDIMI), Santiago E-mail:

\section{Association between motherhood postponement and socioeconomic status}

\begin{abstract}
Background: Delayed motherhood is a common phenomenon in the developed world, where the age at first delivery is around 30 years. In Chile the National Institute of Statistics established that this age has remained around 23 years for more than two decades. Motherhood postponement may be modulated by socioeconomic status. Aim: To determine whether the age at first delivery is higher in a private clinic compared to a public hospital. Patients and Methods: Two cohorts of primiparous women delivering in 1998 and 2008 in the public hospital San Borja Arriarán (HSBA) and a private setting Clinica Las Condes (CLC), were analyzed. Results: The age of all delivering women was significantly lower in HSBA than in CLC in both study periods $(26.3 \pm 0.8$ and $25.7 \pm 0.9$ compared to $31.6 \pm 0.1$ and $32.7 \pm 0.1$ years, respectively). Likewise, the frequency of adolescent pregnancy was significantly higher in HSBA than CLC in both study periods (38.8 and $42.2 \%$ compared to 1.7 and $1.6 \%$ respectively). The age at first delivery was significantly lower in both periods in HSBA (21.8 and 21.3 years compared to 28.6 and 30.6 years, respectively). Excluding primiparous women of less than 20 years, the difference in age was smaller, but remained still significant (24.6 and 24.2 versus 29.9 and 31.0 years, respectively). Conclusions: In Santiago, the postponement of motherhood is more marked among women of high socioeconomic status.
\end{abstract}

(Rev Med Chile 2010; 138: 1240-1245).

Key words: Parity; Pregnancy in adolescence; Socioeconomic factors.
L a demografía de muchos países del mundo se ha visto impactada en las últimas décadas por la postergación de la maternidad, generando que un número progresivamente mayor de mujeres tengan su primer hijo hacia los 30 años de edad. En Suiza, por ejemplo, la edad de las mujeres al momento del primer parto aumentó de 25 a 30,1 años de 1969 a 2006 ${ }^{1}$. En los Estados Unidos de Norteamérica (USA) este fenómeno aunque en forma más atenuada comenzó a observarse en la década de 1970-79, en concomitancia con la introducción de anticoncepción hormonal segura y efectiva. Es así como la proporción de mujeres que tuvo su primer parto sobre los 25 años subió de 19 a 36\% de 1970 a 1982 y la proporción de mujeres aún sin hijos entre los 25 y 34 años aumentó en $56 \%$ en el mismo período de tiempo ${ }^{2}$. Otro estudio realizado en los Estados Unidos de Norteamérica con datos obtenidos entre 1969 y 1994, mostró un aumento de la edad de la mujer al momento del primer parto de 21,3 a 24,4 años y un aumento de las mujeres que tenían su primer hijo desde los 30 años en adelante de 4,1 a $21,2 \%{ }^{3}$. Además, esta misma publicación comunicó que la tendencia a postergar la maternidad ocurría, principalmente, en mujeres con mayor nivel educacional. En efecto, 
Postergación de la maternidad en Chile - A. Fuentes et al

de las mujeres que tuvieron su primer hijo con 30 o más años durante el año 1994, 45,5\% tenía 12 o más años de educación y sólo $2,5 \%$ tenía una escolaridad menor a 12 años ${ }^{3}$.

La postergación de la maternidad se está transformando en un tema de salud pública relevante en el mundo, ya que tiene consecuencias sobre la salud de la madre y del recién nacido. En efecto, al avanzar la edad de la mujer se produce un aumento de la infertilidad ${ }^{4}$, del riesgo de anomalías cromosómicas del feto y de las tasas de aborto ${ }^{5}$, un incremento en la frecuencia y gravedad de las patologías del embarazo, un aumento de la incidencia de mortinatos, de recién nacidos prematuros y de bajo peso al nacer ${ }^{6}$.

En Chile, no se observa un cambio sustancial en la edad de la madre al nacimiento del primer hijo entre 1960 y 20037, (Tabla 1). Este resultado es sorprendente si se considera la evidencia internacional y el aumento de la escolaridad verificado durante estos mismos años en el país, en abierta contradicción con los resultados reportados por Heck y cols ${ }^{3}$. En efecto, en el mismo período de tiempo el nivel educacional en Chile mejoró notoriamente, aumentando la escolaridad de las mujeres entre 25 y 29 años de 6,4 a 11,5 años y el acceso a estudios superiores de 5\% en 1960 a casi $25 \%$ de las mujeres en 2003 (Anuarios de Demografía, Instituto Nacional de Estadísticas de Chile); sin embargo, no observamos un incremento paralelo de la edad al primer parto.
Es posible observar también en la Tabla 1 que en Chile, la edad de la mujer al primer parto varía de acuerdo a su estado civil. En mujeres no casadas la edad promedio de las primíparas fue significativamente menor que la de aquellas que se encontraban casadas al momento de tener el primer parto. Además, el embarazo adolescente es un fenómeno relativamente nuevo, cuya importancia al estudiar la postergación de la maternidad no ha sido suficientemente analizada. El embarazo adolescente se ha mantenido estable en número, su proporción ha aumentado, por disminución de embarazos generales, en especial en la edad de 20-34 años. Por otra parte, el índice de nupcialidad se encuentra en descenso y en la actualidad más de $50 \%$ de los nacimientos ocurre fuera del matrimonio legalmente establecido.

Teniendo estos datos en consideración, el objetivo de esta publicación es evaluar si la condición socioeconómica de la mujer modula su interés en relación a la postergación de la maternidad. La hipótesis alternativa plantea que el nivel socioeconómico de la mujer se asocia en forma directa a la postergación de la maternidad.

\section{Pacientes y Método}

Se diseñó un estudio retrospectivo, con análisis estadístico descriptivo y analítico de la edad de todas las primíparas cuyo parto ocurrió entre el $1^{\circ} \mathrm{de}$ enero y el 31 de diciembre de los años 1998 y 2008

Tabla 1. Escolaridad de mujeres de 25 a 29 años y edad de la madre a la fecha del nacimiento del primer hijo en Chile, 1960-2003

\begin{tabular}{|ccccc|}
\hline Año & $\begin{array}{c}\text { Escolaridad mujeres } \\
\mathbf{2 5 - 2 9} \text { años }\end{array}$ & $\begin{array}{c}\text { Edad primer hijo } \\
\text { global }\end{array}$ & $\begin{array}{c}\text { Edad primer hijo } \\
\text { casadas }\end{array}$ & $\begin{array}{c}\text { Edad primer hijo no } \\
\text { casadas }\end{array}$ \\
\hline 1960 & 6,4 & 23,7 & 23,5 & 21,4 \\
1965 & 6,6 & 23,3 & 22,9 & 21,0 \\
1970 & 7,4 & 22,9 & 22,8 & 21,0 \\
1975 & 8,2 & 22,6 & 22,7 & 21,8 \\
\hline 1980 & 9,2 & 22,6 & 22,8 & 21,7 \\
1985 & 9,8 & 22,8 & 23,4 & 21,8 \\
\hline 1990 & 10,1 & 23,2 & 23,9 & 21,8 \\
\hline 1995 & 10,6 & 23,2 & 24,3 & 21,8 \\
\hline 2000 & 11,3 & 23,3 & 25,5 & 21,7 \\
\hline 2003 & 11,5 & 23,3 & 26,5 & 22,0 \\
\hline
\end{tabular}

Anuarios de Demografía, Instituto Nacional de Estadísticas de Chile. 
en el hospital público Hospital Clínico San Borja Arriarán (HCSBA) y en el centro privado Clínica Las Condes (CLC) caracterizado el primero por la atención de población de nivel socioeconómico bajo y el segundo por la atención de población de nivel socioeconómico alto.

Se comparó la edad promedio y composición etárea de estas mujeres para ambos años dentro de una misma institución entre los años 1998 y 2008, y también entre ambas.

Dada la diferente frecuencia de embarazo adolescente en ambas muestras se ajustó por este factor realizando análisis con las primíparas menores de 20 años de edad incluidas y otro separado excluyendo a este grupo.

En la comparación de medias se usó t de Student y en la de proporciones Chi cuadrado.

El estudio fue autorizado por el Comité Ético Científico del Hospital Clínico San Borja Arriarán (HCSBA).

\section{Resultados}

En HCSBA se observó una baja del número de partos en el período estudiado. Mientras ocurrieron 7.812 partos en 1998, el año 2008 esta cifra disminuyó a 5.784. En cambio, en CLC, ocurrió lo contrario; los partos aumentaron desde 1.316 en 1998 a 1.549 en 2008. Por otra parte, la edad de las parturientas sin distinción de su paridad varió también en sentido contrario en ambos establecimientos. Mientras en HCSBA disminuyó desde 26,31 $\pm 0,78$ a 25,65 $\pm 0,92$ años en CLC aumentó desde $31,61 \pm 0,129$ a $32,73 \pm 0,110$ años $(\mathrm{p}<0,05)$.

Tal como se observa en la Tabla 2 las primíparas representaron un porcentaje significativamente mayor del total de los partos en el HCSBA que en la CLC tanto en el año 1998 como en 2008. Además se observa que en ambos establecimientos este porcentaje creció entre 1998 y 2008.

Tabla 2. Número y proporción de primíparas

\begin{tabular}{|c|c|c|c|c|c|}
\hline \multicolumn{6}{|c|}{ Año 1998} \\
\hline & $\mathbf{N}^{\circ}$ primíparas & $\%$ & $\mathbf{N}^{\circ}$ Multíparas & $\%$ & Total partos \\
\hline HCSBA & 3.282 & 42 & 4.531 & 58 & 7.813 \\
\hline $\mathrm{CLC}$ & 351 & 27 & 965 & 73 & 1.316 \\
\hline \multicolumn{6}{|c|}{ Año 2008} \\
\hline & $\mathbf{N}^{\circ}$ primíparas & $\%$ & $\mathbf{N}^{\circ}$ Multíparas & $\%$ & Total partos \\
\hline HCSBA & 2.596 & 45 & 3.188 & 55 & 5.784 \\
\hline CLC & 514 & 33 & 1.035 & 67 & 1.549 \\
\hline
\end{tabular}

Año 1998

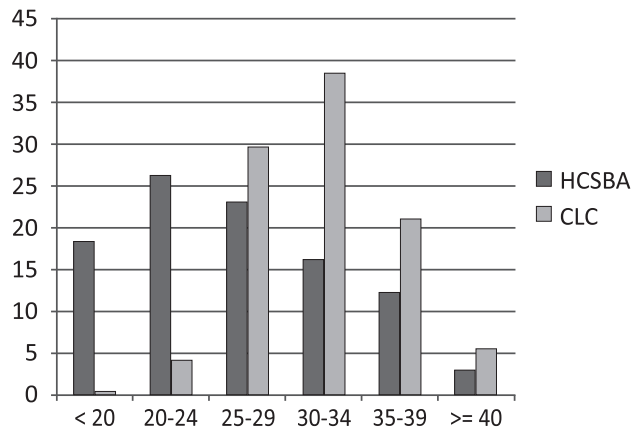

Año 2008

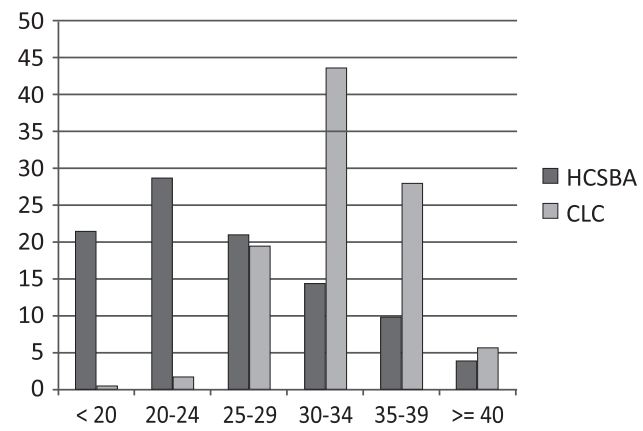

Figura 1. Primípara, según año, grupo etáreo y lugar de ocurrencia del parto. 


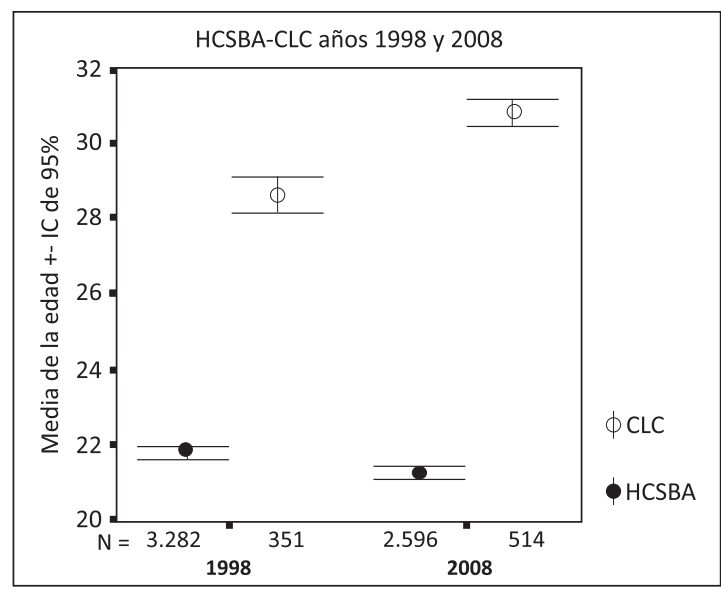

Figura 2. Edad promedio de las primíparas.

En la Figura 1 podemos apreciar la distribución por grupo etáreo de las primíparas. Se observa que en HCSBA predominan las primíparas menores de 30 años de edad constituyendo 67\% el año 1998 y $72 \%$ el año 2008. En cambio en CLC las primíparas mayores de 30 años representaban 65\% el año 1998 y $73 \%$ el año 2008 .

Por otra parte, la proporción de primíparas adolescentes (menores de 20 años de edad) en el hospital público correspondió a 38,8\% del total de las primíparas en el año 1998 y a 42,4\% el año 2008. En la clínica privada esta situación fue muy diferente, ya que estos porcentajes correspondieron al 1,7 y $1,6 \%$ respectivamente.

La Figura 2 ilustra la edad promedio de las primíparas en ambos lugares. Observamos que las primíparas en CLC presentaban una edad significativamente mayor que las primíparas del HCSBA. Es obvio que el embarazo adolescente hace una contribución a esta diferencia; sin embargo, al ajustar los resultados por este factor presentando sólo las primíparas de 20 o más años (Figura 3) persiste una significativa diferencia en la edad de las primíparas en ambos sitios y para los dos años estudiados.

\section{Discusión}

Nuestros hallazgos revelan que en una clínica privada de Santiago, la cual atiende en forma preferencial a pacientes de alto nivel socioeconómico, la edad promedio de las primíparas es significativamente mayor que la registrada en un hospital

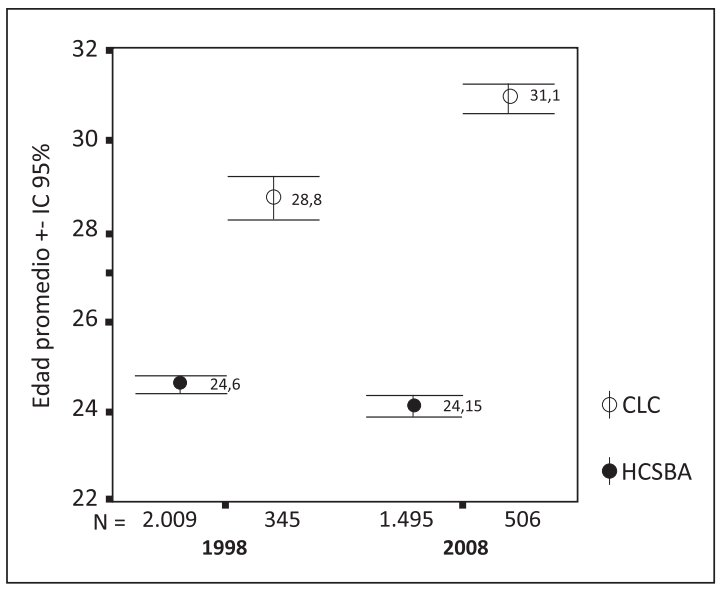

Figura 3. Edad primíparas de 20 y más años.

público de la misma ciudad destinado al segmento socioeconómico bajo y medio bajo. Más importante aun, nuestros hallazgos en HCSBA indican una edad promedio al primer parto muy semejante aunque levemente inferior a la comunicada a nivel nacional por el Instituto Nacional de Estadísticas el año 2003 en Chile. Estos resultados avalan nuestra hipótesis alternativa que planteaba que un alto nivel socioeconómico se asocia en forma directa a la postergación de la maternidad.

Por otra parte, uno de los hechos más llamativos de este reporte es que el embarazo adolescente se presenta con una frecuencia inusitadamente alta en el HCSBA comparado con CLC, datos que concuerdan con los resultados del Censo del año 2002, en donde la razón de proporción de madres adolescentes de 15 a 19 años y la proporción de personas por nivel socioeconómico fue de 0,3 para personas de nivel $\mathrm{ABC} 1$ y de un 1,5, 1,3 y 0,7 para E, D y C3 respectivamente ${ }^{8}$. Este dato probablemente refleje la profunda desigualdad social y económica que se observa en la sociedad chilena en las últimas décadas caracterizada por una alta concentración del ingreso y una cierta estabilidad en el tiempo de esta desigualdad ${ }^{9,10}$. Sin embargo, datos de la Encuesta CASEN 2006 arrojan algunas cifras positivas en este sentido ya que de acuerdo a esta encuesta, la distribución del ingreso autónomo se mantuvo estática entre 1990 y 2003, presentando una alta concentración (cercana a $42 \%$ ) en los hogares pertenecientes al decil (10\%) de mayores ingresos del país. Sin embargo, la medición de 2006 representa un punto de quiebre en esta situación, 
observándose por primera vez en 16 años una mejoría en la distribución del ingreso autónomo que incluye prácticamente cualquier tipo de ingreso que pueda obtener una familia. Pero, a pesar de estos datos el problema persiste si admitimos que el impacto de la pobreza no es equitativo entre los géneros. La misma encuesta CASEN 2006 establece que "si bien la brecha de la pobreza entre hombres y mujeres pasó de $1,4 \%$ en 1990 a $0,4 \%$ en 2000 , volvió a subir durante esta década para ubicarse en $1,2 \%$ en 2006. Esto implica la feminización de la pobreza en los últimos años".

La edad ideal para ser madre ha sido pobremente definida en la literatura ${ }^{11}$, sin embargo, la investigación teórica identifica por un lado la avidez por el consumo, y por el otro la obtención de una carrera para la mujer como las principales variables que explican la postergación del embarazo en muchos países de Europa. Beck y Beck $^{12}$ señalan que la individualización significa que los seres humanos son liberados de los roles de género tradicionales, y deben construirse una existencia propia a través del mercado laboral, y de la formación y de la movilidad educativas, en detrimento de las relaciones amorosas y familiares. Otro estudio que compara la postergación de la maternidad en mujeres profesionales de Caracas, Venezuela y Santiago de Chile ${ }^{13}$ establece que "la maternidad es una selección que se suspende, niega y/o retoma por el desarrollo de una individualidad o de un "yo", que toma distancia del carácter indiscutible e impostergable que tenía la maternidad en generaciones anteriores. La postergación de la maternidad está relacionada con el desarrollo de una biografía a través del mercado laboral y académico. La decisión de ser madre se independiza de lo tradicionalmente adscrito a las mujeres. A diferencia de generaciones pasadas, se requiere conocerse y desarrollarse a si mismas de forma integral antes de tener hijos".

Por otra parte, el censo en USA informó que la edad al primer parto aumentó de 21,4 años (en 1970) a 25 años (en 2006) ${ }^{14}$ y aunque 25 años no es una edad avanzada se debe tener en cuenta que en USA, al igual que en Chile, hay aun una alta tasa de embarazo adolescente la cual hace descender este promedio. Estos datos comparan bien con lo que se observó en el HCSBA en el que al ajustar los datos por el fenómeno embarazo adolescente el promedio de edad de las primíparas sube de casi 22 años a 25.
De acuerdo a los últimos datos del INE disponibles (año 2003), la edad promedio al primer parto es 23,3 años en Chile. Nuestro estudio revela que esta realidad puede ser matizada si se ajusta los datos por nivel socio-económico. Las principales causas de esta situación tienen que ver con que hoy en día para muchas mujeres tener hijos interfiere con el acceso a ofertas laborales culturales y sociales. En la medida que los sectores más empobrecidos de la población chilena tengan acceso real a la educación y la carrera esta realidad debiera cambiar sustancialmente.

Sin embargo, vale la pena preguntarse si la postergación de la maternidad representa un fenómeno positivo para la sociedad. A juzgar por datos provenientes de países en donde este fenómeno es ya una realidad desde hace más de una década, esto no es así. El envejecimiento de la población, el embarazo de alto riesgo ${ }^{15}$, el aumento en las tasas de aborto espontáneo ${ }^{16}$, e infertilidad ${ }^{17}$ y el esfuerzo que deben desplegar los gobiernos para incentivar la maternidad son temas de alto costo para el estado.

Habría sido interesante disponer de la información necesaria para ajustar los datos por variables relacionadas como número de años de escolaridad, número de hijos deseado y estado civil, pero no fue posible debido a la ausencia de registros al respecto.

En suma, podemos decir que la postergación de la maternidad es un tema que se ha ido instalando lentamente en la sociedad chilena. Lo anterior se debe, al menos en parte, a la alta frecuencia de embarazo adolescente observada especialmente en la última década en los sectores populares de Chile. Las consecuencias de un embarazo temprano para el proyecto personal de una mujer dependerán fundamentalmente de su nivel socioeconómico y la complejidad de sus redes sociales de apoyo. El nivel socioeconómico y paralelamente el grado de escolaridad son parte de las variables de mayor impacto sobre el acceso a mejores oportunidades de trabajo y formación académica y, por lo tanto, tienen un rol fundamental en la decisión de postergar la maternidad.

\section{Referencias}

1. Kalberer U, Baud D, Fontanet A, Hohlfeld P, De Ziegler D. Birth records from Swiss married couples analyzed over the past 35 years reveal an aging of first-time mo- 
thers by 5.1 years while the interpregnancy interval has shortened. Fertil Steril 2009; 92: 2072-3.

2. Baldwin WH, Nord CW. Delayed childbearing in the US: facts and fictions. Popul Bull 1984; 39: 1-42.

3. Heck KE, Schoendorf KC, Ventura SJ, Kiedly JL. Delayed childbearing by educational level in the United Status, 1969-1994. Matern Child Health J 1997; 1: 81-8.

4. Baird DT, Collins J, Egozcue J, Evers LH, Gianarioli L, Leridon $\mathrm{H}$, et al. Fertility and aging. Hum Reprod Update 2005; 11: 261-76.

5. Gindoff PR, Jewelewicz R. Reproductive potential in older woman. Fertil Steril 1986; 46 (6): 989-1001.

6. Hansen JP. Older maternal age and pregnancy outcome: a review of the literature. Obstet Gynecol Surv 1986; 41: 726-742.

7. Anuarios de Demografía, Instituto Nacional de Estadísticas de Chile.

8. W B. Chile Poverty and Income Distribution in a High Growth Economy The case of Chile" Report No 22037 CH August 30, 2001.

9. Solimano A, Torche A. La distribución del ingreso en Chile 1987-2003: análisis y consideraciones de política.
Documentos de Trabajo (Banco Central de Chile), No. 480, 2008.

10. Gustafsson S. Optimal age at motherhood. Theoretical and empirical considerations on postponement of maternity in Europe. Journal of Population Economics 2001; 14, 2: 225-47.

11. Beck U, Beck E (2001). En: El normal caos del amor. Paidós, Barcelona, España.

12. Montilva M. Postergación de la maternidad de mujeres profesionales jóvenes en dos metrópolis latinoamericana. Revista Internac Filosof Iberoameric Teor Soc 2008; 13: 69-79.

13. Centro Nacional de Estadísticas de Salud (NCHS).

14. Karsan S. Early education is de rigueur in planning latelife pregnancies. Hum Reprod Genet Ethics 2009; 15: 60-7.

15. Hurwitz Jm, Jindal S, Greenseid K, Berger D, Brooks A, Santoro N, et al. Reproductive Aging is Associated With Altered Gene Expression in Human Luteinized Granulosa Cells. Reprod Sci 2010; 17: 56-67.

16. Dupas C, Christin-Maitre $S$. What are the factors affecting fertility in 2008? Ann Endocrinol 2008; 69: 57-61. 